Research Paper

\title{
Does the Loss of ARIDIA (BAF-250a) Expression in Endometrial Clear Cell Carcinomas Have Any Clinicopathologic Significance? A Pilot Assessment
}

\author{
Oluwole Fadare ${ }^{凶}$, Idris L. Renshaw, Sharon X. Liang \\ 1. Department of Pathology, Microbiology and Immunology, and Department of Obstetrics and Gynecology, Vanderbilt \\ University School of Medicine, Nashville, TN. \\ 2. Vanguard Pathology Associates, Austin, TX \\ 3. Department of Pathology and Laboratory Medicine, Hofstra North Shore-LIJ School of Medicine, Lake Success, NY
}

$\checkmark$ Corresponding author: Oluwole Fadare, MD., PMI Dept, MCN C-2310D, Vanderbilt University Medical Center, 116121 st Avenue S, Nashville, TN 37232. E-mail: oluwolefadare@yahoo.com

( ) Ivyspring International Publisher. This is an open-access article distributed under the terms of the Creative Commons License (http://creativecommons.org/ licenses/by-nc-nd/3.0/). Reproduction is permitted for personal, noncommercial use, provided that the article is in whole, unmodified, and properly cited.

Received: 2012.01.23; Accepted: 2012.03.04; Published: 2012.03.10

\begin{abstract}
SWI/SNF chromatin-modification complexes use the energy of ATP hydrolysis to remodel nucleosomes and to affect transcription and several cellular processes. Accordingly, their loss of function has been associated with malignant transformation. ARIDIA (the expression of whose product, BAF250a, a key complex component, is lost when mutated) has recently been identified as a tumor suppressor gene that is mutated in $46-57 \%$ of ovarian clear cell carcinoma (CCC). The purposes of this study are to assess the frequency of loss of BAF250a expression in endometrial CCC and whether this loss has any discernable clinicopathologic implications. 34 endometrial carcinomas with a CCC component (including 22 pure CCC, 8 mixed carcinomas with a 10\% CCC component, and 4 carcinosarcomas with a CCC epithelial component), were evaluated by immunohistochemistry using a monoclonal antibody directed against the human BAF250a protein. 5 (22.7\%) of the 22 pure CCC were entirely BAF250a negative, whereas the remainder showed diffuse immunoreactivity. None of 4 carcinosarcomas and only I (I2.5\%) of the 8 mixed carcinomas were BAF250a negative. There was no discernable relationship between BAF250a immunoreactivity status and tumor architectural patterns (solid, papillary or tubulocystic areas) or cell type (flat, hobnail or polygonal). Of the 22 patients with pure CCC, 14, 2, 3, and 3 were International Federation of Gynecology and Obstetrics stages I, II, III and IV respectively. Interestingly, all 5 BAF250a negative cases were late stage [stages III or IV] as compared with I of I7 BAF250a positive cases $(p=0.0002)$. Thus, $83 \%(5 / 6)$ of all late stage cases were BAF250a [-], as compared with $0(0 \%)$ of the 16 early stage (I or II) cases $(p=.0002)$. BAF250a negative and positive cases did not show any statistically significant difference regarding patient age and frequency of lymphovascular invasion or myometrial invasion. As may be anticipated from the concentration of late stage cases in the BAF250a negative group, patient outcomes were worsened in that group on univariate analysis. In conclusion, we found in this pilot assessment that $22.7 \%$ of endometrial CCC displays complete loss of BAF250a expression. There was a disproportionate concentration of BAF250a negative cases in the late stage group, with the attendant possibility of an associated worsened prognosis for those CCC patients whose tumors are BAF250a negative. These preliminary findings suggest the need for larger analyses to evaluate the prognostic significance, if any, of the loss of BAF250a expression in this rare histotype of endometrial cancer.
\end{abstract}

Key words: BAF250a, ARID1A, endometrial cancer 


\section{INTRODUCTION}

In recent years, there have been significant advances in deciphering the molecular bases for the 2 most common histotypes of endometrial carcinoma: endometrioid carcinoma and serous carcinoma $(1,2)$. The molecular underpinnings of endometrial clear cell carcinomas (CCC), in contrast, remain largely unclear (3). This may be related to its rarity, as CCC constitute no more than between 1 and $7 \%$ of endometrial carcinomas $(4,5)$. Alternatively, the interobserver variability associated with its diagnosis may have historically represented significant impediments to segregating a biologically pure dataset (6). In one molecular analysis, cases of mixed CCC/ endometrial endometrioid carcinoma (EEC) and mixed $\mathrm{CCC} /$ endometrial serous carcinomas (ESC) displayed such molecular similarities in the CCC and non-CCC components that the authors remarked that CCC may "represent a heterogeneous group of tumors that arise via different pathogenetic pathways" (7). Nevertheless, the fact that CCC is morphologically distinctive (5), displays noteworthy clinical associations such as an increased risk of thromboembolic events $(8,9)$, and shares gene and protein expression profiles with its ovarian counterparts, all indicate that it is indeed a distinct entity. Additionally, limited data suggests that even minor components of CCC may adversely impact the prognoses of patients with otherwise pure endometrioid carcinomas $(10,11)$. There are no widely accepted guidelines for the management of CCC patients, and reported patient outcomes have historically been widely variable (12). These findings suggests the need for a more extensive characterization of the biologic basis for CCC, not only to identify potential molecular targets for directed therapies, but also to identify proteins whose expression patterns may classify CCC patients into prognostically relevant subgroups.

The mechanism by which the large amount of DNA in eukaryotic cells is fitted into the confines of the small nucleus in each cell involves a high order compaction, which at its most basic subunit, entails DNA being wrapped around a histone octamer to form a nucleosome (13-17). Nucleosomes are further joined by linker DNA to form highly complex supercoiled structures (heterochromatin), which renders individual genes relatively inaccessible to the cellular transcription machinery. Chromatin remodeling, which serves to provide access to these genes by sequence-specific transcription factors, may be accomplished by covalent modifications of the histones (through acetylation, phosphorylation and methylation), or the use of ATP-dependent energy to mobilize the nucleosomes (14-16). The SWI/SNF complex (mating type switching/sucrose non-fermenting) belongs to the latter class, and is an evolutionarily conserved multi-unit structure whose subunits may participate in transcriptional activation or repression of numerous target genes (13-15). In addition to transcriptional regulation and various aspects of carcinogenesis and progression, SWI/SNF complexes are also involved in DNA repair, replication and recombination, mitotic gene regulation, cellular differentiation and viral gene expression (13-17). BAF250a, a subunit of the SWI/SNF complex with ATPase activity, is encoded by the adenine-thymine (AT)-rich interative domain containing protein 1A (ARID1A) gene, and low frequency somatic mutations of this gene have been identified in a wide spectrum of human neoplasms (18). Recently Jones et al reported that ARID1A mutations are present in $57 \%$ of ovarian CCC and that the patterns of inactivating mutation were suggestive of ARID1A being a tumor suppressor gene (19). In a nearly concurrent publication, Wiegand et al found that $46 \%$ of ovarian CCC, $30 \%$ of endometrioid carcinomas and $0 \%$ of high grade serous carcinomas displayed ARID1A mutations (20). Additionally, the presence of ARID1A mutations was found to significantly correlate with loss of expression of the BAF250a protein as assessed by immunohistochemistry (20). Reports published after these seminal papers have subsequently confirmed the ARID1A gene mutation and/or loss of expression of the BAF250a protein in a significant subset of ovarian CCC (21-26). Since ovarian and endometrial CCC are known to share numerous attributes at both the genotypic and phenotypic levels (27-29), it can be anticipated that endometrial CCC will similarly display loss of BAF250a expression in a subset. In one study, Guan et al (30) reported that $26 \%$ of low grade uterine endometrioid carcinomas lack expression of BAF250a; $40 \%$ were found to display inactivating ARID1A mutations, and none of 12 endometrial serous carcinomas displayed these mutations (30). Recently, Wiegand et al reported that loss of BAF250a expression is common in high grade endometrial carcinomas, including $29-39 \%$ of endometrial endometrioid carcinomas, $18 \%$ of endometrial serous carcinomas, and $26 \%$ of endometrial CCC (31). However, these analyses did not evaluate whether the loss of BAF250a has any clinicopathologic correlations. The purposes of the current study are to assess the frequency of loss of BAF250a expression in endometrial CCC, and whether this loss has any discernable clinicopathologic implications.

\section{MATERIALS AND METHODS}

This study was based on an immunohistochem- 
ical analysis of archived pathologic material. Slides for 34 endometrial carcinomas with a clear cell component were retrieved from the files of the Departments of Pathology at Vanderbilt University Medical Center (Nashville, TN), Brooke Army Medical Center (Ft Sam Houston, TX), Stony Brook University Medical Center (Stony Brook, NY), Wilford Hall Medical Center (San Antonio, TX), and Vanguard Pathology Associates (Austin, TX). The 34 cases included 22 pure CCC (figure 1A), 8 mixed carcinomas with a $10 \%$ CCC component (Mixed CCC), and 4 carcinosarcomas with a CCC epithelial component. For the mixed CCC group, which included 4 mixed ESC/CCC, 1 mixed CCC/ undifferentiated carcinoma, 2 mixed EEC/CCC, and 1 mixed ESC/EEC/CCC, only a slide with the CCC component was evaluated immunohistochemically in each case. Several of the cases in this study have been the subject of immunohistochemical analyses in previous reports from our group $(8,32)$, and were extensively reviewed in the context of those studies and the current analysis. Basic clinicopathologic information for each case was documented, including patient age, International Federation of Gynecology and Obstetrics (FIGO) stage, presence or absence of lymphovascular and myometrial invasion, adjuvant treatments, and patient outcomes

Immunohistochemistry was performed on one section from each of the study cases. Five micron-thick sections were placed on charged slides, deparaffinized, and rehydrated. All steps besides dehydration, clearing, antigen retrieval and coverslipping were performed on the Leica Bond Max Immunohistochemical stainer. Slides are deparaffinized. Heat induced antigen retrieval was performed on the Bond Max using their Epitope Retrieval 2 solution for 30 minutes. Slides were incubated with a BAF250a primary antibody for one hour at 1:50 dilution. The BAF250a antibody used was a mouse monoclonal antibody raised against a recombinant protein corresponding to amino acids 600-1018 of human BAF250a (PSG3, sc-32761, Santa Cruz Biotechnology, Inc., Santa Cruz, CA). The Bond Polymer Refine detection system was used for visualization. Slides were then dehydrated, cleared and coverslipped.

BAF250a expression patterns were evaluated based on previously described concepts (20). Nuclear BAF250a expression is normally present in lymphocytes, endothelial cells, and stromal cells. These cells accordingly served as internal positive controls, and the complete absence of staining in both these positive control components and the tumor was used to denote one or more technical deficiencies that disqualified the whole assay. For the tumors, staining pattern interpretations were performed on the epithelial tumor cells only. Any amount of unequivocal nuclear immunoreactivity was considered to be BAF250a positive (BAF250a[+]). Conversely, a case was classified as BAF250a negative (BAF250a[-]) if all the epithelial cells displayed no immunoreactivity. BAF250a $[+]$ cases were further classified as displaying mild, moderate or extensive immunoreactivity. Mild immunoreactivity was said to be present when less than $33 \%$ of the tumor on the slide displayed any staining or staining was diffusely light irrespective of the distribution. Cases classified as displaying moderate immunoreactivity displayed at least moderate intensity of staining in $33 \%-66 \%$ of the tumor on the slide. Cases classified as displaying extensive immunoreactivity displayed at least moderate intensity of staining in greater than $66 \%$ of the tumor on the slide.

BAF250a [+] and BAF250a[-] negative cases were compared regarding a variety of clinicopathologic variables using Fisher's Exact or Student's $t$ tests as appropriate A 2-tailed p value of less than 0.05 was considered as statistically significant in all relevant analyses. This study was approved by the institutional review board at Vanderbilt University.

\section{RESULTS}

$5(22.7 \%)$ of 22 pure CCC were entirely BAF250a $[-]$, whereas the remainder showed extensive immunoreactivity. The expression patterns appeared to be an "all or nothing" phenomenon, in that cases were either diffusely positive or entirely negative (figures 1B-D). There was no discernable relationship between predominant tumor architectural patterns (solid, papillary or tubulocystic areas) or cell type (flat, hobnail or polygonal) and BAF250a immunoreactivity. In BAF250a positive cases, both the stroma and epithelia were positive. None of 4 carcinosarcomas and only 1 $(12.5 \%)$ of 8 mixed carcinomas were BAF250a negative. Since the latter did not appear to be broadly different from the pure CCC group regarding frequency of BAF250a negativity, these groups were not considered any further. In the one BAF250a negative mixed carcinoma (a mixed ESC/CCC), both components were negative.

Clinicopathologic information for the patients in the pure CCC group is summarized in table 1 . Of the 22 pts with pure CCC, 14, 2, 3, and 3 were International Federation of Gynecology and Obstetrics (FIGO) stages 1, II, III and IV respectively. Interestingly, all 5 BAF250a negative cases were late stage [FIGO stage III or IV] as compared with 1 of 17 BAF250a positive cases $(\mathrm{p}=0.0002)$, table 2 . 

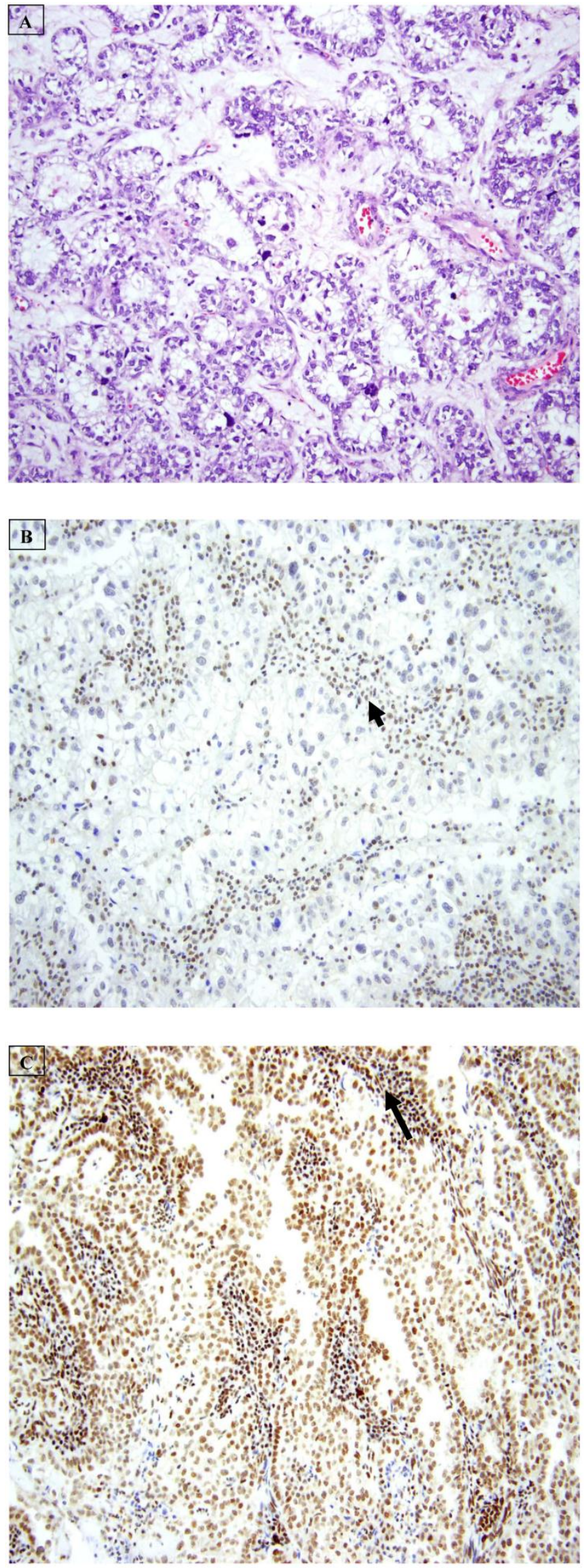

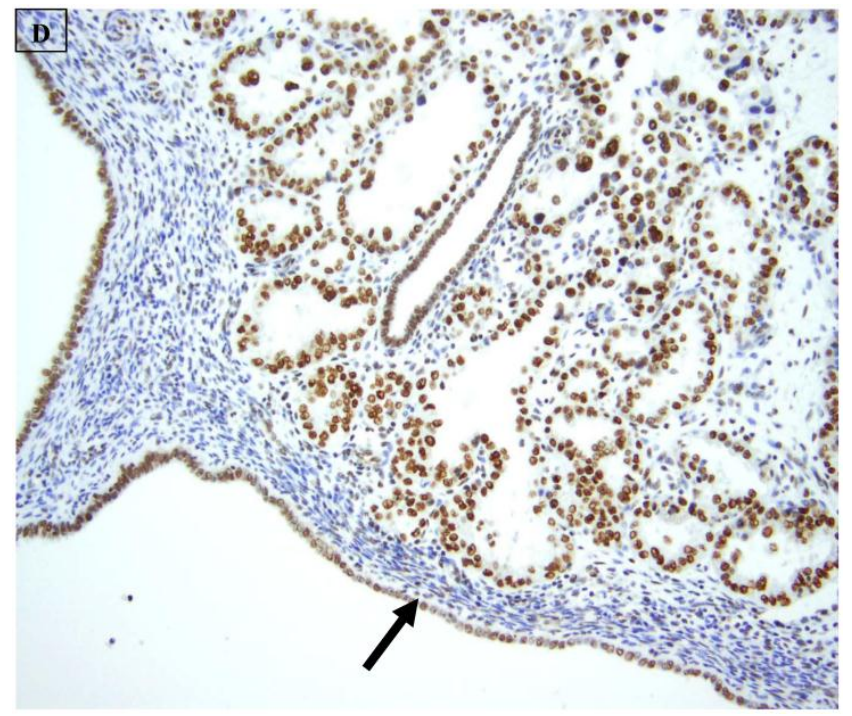

Figure I. A: A representative image of endometrial clear cell carcinoma (hematoxylin and eosin, original magnification: 200x). B: Complete loss of expression of the BAF250a protein in endometrial clear cell carcinoma. Stromal inflammatory cells (arrow) are diffusely immunoreactive (immunoperoxidase, original magnification: 200x). C: Diffuse expression of the BAF250a protein in endometrial clear cell carcinoma. Stromal inflammatory cells (arrow) are also diffusely immunoreactive (immunoperoxidase, original magnification: 200x). D: Diffuse expression of the BAF250a protein in endometrial clear cell carcinoma. Non-neoplastic endometrial epithelial cells (arrow) are also immunoreactive (immunoperoxidase, original magnification: 200x)

Thus, $83 \%(5 / 6)$ of all late stage cases were BAF250a negative, as compared with $0(0 \%)$ of the 16 early stage (I or II) cases ( $p=.0002)$. 1 of 5 BAF250a negative cases showed lymphovascular invasion, as compared with 6 of 17 BAF250a positive cases, a statistically insignificant difference. A similarly insignificant difference between the 2 groups was found regarding patient age and the frequency of myometrial invasion. As may be anticipated from the concentration of late stage cases in the BAF250a negative group, patient outcomes were worsened, at least on univariate analysis, in that group. Patient outcomes for the pure CCC group were as follows: Alive with disease, 6 patients; No evidence of disease, 11 patients; Dead of disease, 4 patients; follow-up unavailable, 1 patient. $60 \%$ of the 5 BAF250a negative patients were dead of disease (the other 2 had no evidence of disease), as compared with only $1(6.25 \%)$ of 16 BAF250a positive patients for whom follow-up information was available $(\mathrm{p}=0.02)$. 
Table I. BAF250a immunoreactivity in cases of pure clear cell carcinoma

\begin{tabular}{|c|c|c|c|}
\hline Parameters & All cases & BAF250a [-] & BAF250a $[+]$ \\
\hline Number of cases & 22 & 5 & 17 \\
\hline \multicolumn{4}{|l|}{ Patient Age } \\
\hline mean & 70 & 63 & 69 \\
\hline median & 72 & 69 & 67 \\
\hline Range & $54-87$ & $61-78$ & $54-87$ \\
\hline \multicolumn{4}{|l|}{ Lymphovascular } \\
\hline Yes & 7 & 1 & 6 \\
\hline No & 15 & 4 & 11 \\
\hline \multicolumn{4}{|l|}{ Myometrial inva- } \\
\hline Yes & 16 & 5 & 11 \\
\hline No & 6 & 0 & 6 \\
\hline \multicolumn{4}{|l|}{ Predominant } \\
\hline Solid & 4 & 0 & 4 \\
\hline Papillary & 9 & 3 & 6 \\
\hline Tubulocystic & 2 & 0 & 2 \\
\hline Glandular & 7 & 2 & 5 \\
\hline \multicolumn{4}{|l|}{ FIGO Stage } \\
\hline I & 14 & 0 & 14 \\
\hline II & 2 & 0 & 2 \\
\hline III & 3 & 3 & 0 \\
\hline IV & 3 & 2 & 1 \\
\hline Late stage (III, IV) & 6 & 5 & 1 \\
\hline \multicolumn{4}{|l|}{ Follow-up } \\
\hline Mean (months, & $47(11-82)$ & $46(18-46)$ & $56.5(11-82)$ \\
\hline Alive with Dis- & 6 & 0 & 6 \\
\hline No evidence of & 11 & 2 & 9 \\
\hline Dead of Disease & 4 & 3 & 1 \\
\hline Unavailable & 1 & 0 & 1 \\
\hline \multicolumn{4}{|l|}{ Adjuvant chemo- } \\
\hline Yes & 11 & 4 & 12 \\
\hline No & 2 & 0 & 2 \\
\hline Unknown & 9 & 1 & 8 \\
\hline
\end{tabular}

Table 2: A comparison of BAF250a[+] and BAF250a[-] cases regarding selected clinicopathologic variables.

\begin{tabular}{llll}
\hline Feature & BAF250a [-] & BAF250a[+] & P value* \\
\hline $\begin{array}{l}\text { Average patient Age } \\
\begin{array}{l}\text { Lymphovascular invasion } \\
\text { present }\end{array}\end{array}$ & $1 / 5$ & 69 & NS \\
$\begin{array}{l}\text { Myometrial invasion pre- } \\
\text { sent }\end{array}$ & $5 / 5$ & $11 / 17$ & $\mathrm{NS}$ \\
$\begin{array}{l}\text { Late stage (stage III or IV) } \\
\text { Dead of Disease }\end{array}$ & $5 / 5$ & $1 / 17$ & 0.0002 \\
\hline
\end{tabular}

* Fisher's Exact test (univariate analysis); NS: comparison not statistically significant

\section{DISCUSSION}

Since SWI/SNF complexes play significant roles in cell-cycle control, cellular differentiation, DNA replication, recombination, and repair, it can be expected that non-functional or dysfunctional complexes may contribute to malignant transformation. Evidence of the tumor suppressor activity of SWI/SNF complexes include the loss of expression of complex subunits in some cancer cell lines, genetic or epigenetic alterations of associated genes in some cancers, the promotion of tumorigenesis in animal knock-out models, and the direct involvement of SWI/SNF complexes in the regulation of numerous cancer-related target pathways (13-16). SNF, a highly conserved core subunit of the SWI/SNF complex, is inactivated through biallelic deletions or truncating mutations in most cases of malignant rhabdoid tumor, a highly aggressive pediatric malignancy (14-16). SNF mutations have also been described in medulloblastomas, choroid plexus carcinomas, central primitive neuroectodermal tumors, hepatoblastomas, epithelioid sarcomas, poorly differentiated chordomas, meningiomas, familial schwannomatosis, undifferentiated sarcomas, extraskeletal myxoid chondrosarcomas, and the blast crisis phase of chronic myeloid leukemia $(15,16)$. PBRM1, the gene that encodes BAF180, another SWI/SNF complex subunit, is the $2^{\text {nd }}$ most frequently mutated gene $(41 \%)$ in renal cell carcinomas (33), and inactivating PBRM1 mutations have been identified in both renal cell and breast carcinoma cell lines $(33,34)$. As previously noted, ARID1A mutations have been identified in a wide variety of tumors (18-20). Inactivating mutations in the gene that encodes BRG1, another SWI/SNF subunit have been identified in lung carcinoma, medulloblastoma and malignant rhabdoid tumors as well as cancer cell lines from a variety of tumor types (15). There is evidence that SWI/SNF complexes participate in and is involved in regulating several cancer-related pathways (including the retinoblastoma and Hedgehog pathways, interferon-beta and nuclear-hormone receptor signaling, among others), through their interaction with important proto-oncogenes and tumor suppressor genes $(13,15)$. Finally, there is some evidence that SWI/SNF complexes are involved in the promotion of tumor metastases through their interactions with cellular cytoskeletal structure in a manner that affects motility, as well as their interactions with the potentially metastasis-associated glycoprotein, CD44 (15). The myriad ways in which alterations of the SWI/SNF complexes are involved in human neoplasia, are reviewed in detail elsewhere (13-17). 
The concept that the mutational and/or expression status of some SWI/SNF subunits and associated genes may have prognostic significance, is a natural avenue for investigative efforts, given the aforementioned roles of SWI/SNF as putative tumor suppressors. This possibility presents the opportunity for better prognostication by segregating those patients that may require unconventional or even more aggressive therapeutic intervention. Additionally, given the reversible nature of the epigenetic silencing of some SWI/SNF-associated genes in some tumors (subunit BRM, for example [35]), the maximal efficacy of molecularly-targeted therapies may be best achieved in specific patient subsets. Loss of expression of BRM and/or BRG1, both of which are subunits of the SWI/SNF complex, has already been reported to be associated with poor prognosis in patients with lung carcinomas independent of stage $(36,37)$. In one study of head and neck cancers, frequent chromosomal deletion at 9p24, the locus for the BRM gene, was detected and was associated with worsened prognosis (38). Loss of SNF5 has been associated with poor prognosis in patients with malignant melanoma (39), and aberrant expression of the BRM and BRG1 genes has been associated with prostate cancer development and progression (40).

Published data on the clinicopathologic significance of BAF250a loss of expression is somewhat conflicting, at least as they relate to ovarian CCCs $(21,23,24,26)$. Three studies found no correlation between loss of BAF250 a expression and a variety of clinicopathologic variables, including the patient age, stage, survival, tumor size and laterality, presence of residual tumor after initial surgery, response to chemotherapy, nodal metastases, and histological patterns, each of which were evaluated in at least 1 study $(21,23,26)$. However, in a recent study, Katagiri et al (24) found loss of BAF250a to be a significant negative prognostic factor. The authors evaluated 60 ovarian CCC for BAF250 expression by immunohistochemistry (24). On univariate analysis, loss of BAF250a was significantly correlated with advanced stage, high CA125 levels, shorter progression-free and overall survival in patients with platinum-based chemotherapeutic regimens, chemoresistance and not patient age or status of residual tumor (24). Additionally, only loss of BAF250a expression was a predictor of progression free survival on multivariate analysis (24).

In the current study, we evaluated the frequency of loss of BAF250a expression in endometrial CCC, and assessed whether loss of expression of this protein has any clinical or pathologic significance. We found $22.7 \%$ of pure endometrial CCC to be entirely
BAF250a negative, a figure that is largely similar to the $26 \%$ reported by Wiegand et al in the only other analysis of the subject (31). Regarding a potential correlation with clinicopathologic variables, we found no significant association between BAF250a expression and patient age, frequency of lymphovascular or myometrial invasion, and histologic architectural patterns. However, we identified a statistically significant association with FIGO stage, as patients with BAF250a negative tumors were significantly more likely to be advanced stage on univariate analysis. This apparent concentration of BAF250a negative cases in the late stages was reflected in the patients' worsened outcomes. However, larger analyses that would allow for multivariate stratification are required to definitively answer this question.

In summary, we report here for the first time that loss of BAF250a expression, which was seen in $22.7 \%$ of endometrial CCC, may have clinicopathologic significance. The current study is a pilot assessment that is limited by the small data size. However, some noteworthy and intriguing trends were discernable, including the disproportionate concentration of BAF250a negative cases in the late stage group and the attendant possibility of an associated worsened prognosis. These preliminary findings suggest the need for larger analyses to evaluate the prognostic significance, if any, of the loss of BAF250a expression in this rare histotype of endometrial cancer. The fact that BAF250a expression is lost in only a small percentage of endometrial CCC may suggest that ARID1A mutations plays a significant role in only a small proportion of CCC, or that these mutations represent only a small component of the genesis of this specific tumor type. It may also bolster the argument that endometrial CCC represents a phenotype that arises via a multitude of different pathways $(3,7)$, with no one pathway being notably dominant. However, it is unclear if those clear cell carcinomas whose pathogenesis does involve ARID1A mutations, represents a clinicopathologically distinct group with definable characteristics.

\section{Conflict of Interest}

The authors have declared that no conflict of interest exists.

\section{References}

1. Fadare $\mathrm{O}$, Zheng $\mathrm{W}$. Insights into endometrial serous carcinogenesis and progression. Int J Clin Exp Pathol 2009;2:411-32

2. Hecht JL, Mutter GL. Molecular and pathologic aspects of endometrial carcinogenesis. J Clin Oncol. 2006;24:4783-9

3. Fadare O. The Molecular Pathogenesis of Endometrial Clear Cell Carcinoma: Unclear, Uncertain and Possibly Heterogeneous. Expert Review of Obstetrics \& Gynecology 2012;7:109-112 
4. Silva EG, Deavers MT, Malpica A. Undifferentiated carcinoma of the endometrium: a review. Pathology. 2007;39:134-8

5. Clement PB, Young RH. Non-endometrioid carcinomas of the uterine corpus: a review of their pathology with emphasis on recent advances and problematic aspects. Adv Anat Pathol. 2004 May;11(3):117-42.

6. Fadare O, Parkash V, Dupont WD, Acs G, Atkins KA, Irving JA, et al. The diagnosis of endometrial carcinomas with clear cells by gynecologic pathologists: an assessment of interobserver variability and associated morphologic features. Am J Surg Pathol, in press.

7. An HJ, Logani S, Isacson C, Ellenson LH. Molecular characterization of uterine clear cell carcinoma. Mod Pathol. 2004;17:530-7.

8. Fadare O, Renshaw IL, Liang SX. Expression of tissue factor and heparanase in endometrial clear cell carcinoma: possible role for tissue factor in thromboembolic events. Int J Gynecol Pathol. 2011;30:252-61.

9. Lee L, Garrett L, Lee H, Oliva E, Horowitz N, Duska LR. Association of clear cell carcinoma of the endometrium with a high rate of venous thromboembolism. J Reprod Med. 2009;54:133-8.

10. Quddus MR, Sung CJ, Zhang C, Lawrence WD. Minor serous and clear cell components adversely affect prognosis in "mixed-type" endometrial carcinomas: a clinicopathologic study of 36 stage-I cases. Reprod Sci. 2010;17:673-8.

11. Fadare O. Minor serous or clear cell components in early stage endometrioid adenocarcinoma: Is it ever insignificant?. Expert Review of Obstetrics \& Gynecology 2010;5:653-656.

12. Gadducci A, Cosio S, Spirito N, Cionini L. Clear cell carcinoma of the endometrium: a biological and clinical enigma. Anticancer Res. 2010;30:1327-34.

13. Halliday GM, Bock VL, Moloney FJ, Lyons JG. SWI/SNF: a chromatin-remodelling complex with a role in carcinogenesis. Int J Biochem Cell Biol. 2009;41:725-8.

14. Roberts CW, Orkin SH. The SWI/SNF complex--chromatin and cancer. Nat Rev Cancer. 2004;4:133-42.

15. Wilson BG, Roberts CW. SWI/SNF nucleosome remodellers and cancer. Nat Rev Cancer. 2011;11:481-92

16. Klochendler-Yeivin A, Muchardt C, Yaniv M. SWI/SNF chromatin remodeling and cancer. Curr Opin Genet Dev. 2002;12:73-9

17. Reisman D, Glaros S, Thompson EA. The SWI/SNF complex and cancer. Oncogene. 2009;28:1653-68

18. Jones S, Li M, Parsons DW, Zhang X, Wesseling J, Kristel P, Schmidt MK, Markowitz S, Yan H, Bigner D, Hruban RH, Eshleman JR, Iacobuzio-Donahue CA, Goggins M, Maitra A, Malek SN, Powell S, Vogelstein B, Kinzler KW, Velculescu VE, Papadopoulos N. Somatic mutations in the chromatin remodeling gene ARID1A occur in several tumor types. Hum Mutat. 2012;33:100-3

19. Jones S, Wang TL, Shih IeM, Mao TL, Nakayama K, Roden R, Glas R, Slamon D, Diaz LA Jr, Vogelstein B, Kinzler KW, Velculescu VE, Papadopoulos N. Frequent mutations of chromatin remodeling gene ARID1A in ovarian clear cell carcinoma. Science. 2010;330(6001):228-31

20. Wiegand KC, Shah SP, Al-Agha OM, Zhao Y, Tse K, Zeng T, Senz J, McConechy MK, Anglesio MS, Kalloger SE, Yang W, Heravi-Moussavi A, Giuliany R, Chow C, Fee J, Zayed A, Prentice L, Melnyk N, Turashvili G, Delaney AD, Madore J, Yip S, McPherson AW, Ha G, Bell L, Fereday S, Tam A, Galletta L, Tonin PN, Provencher D, Miller D, Jones SJ, Moore RA, Morin GB, Oloumi A, Boyd N, Aparicio SA, Shih IeM, Mes-Masson AM, Bowtell DD, Hirst M, Gilks B, Marra MA, Huntsman DG. ARID1A mutations in endometriosis-associated ovarian carcinomas. N Engl J Med. 2010;363:1532-43.

21. Lowery WJ, Schildkraut JM, Akushevich L, Bentley R, Marks JR, Huntsman D, Berchuck A. Loss of ARID1A-Associated
Protein Expression is a Frequent Event in Clear Cell and Endometrioid Ovarian Cancers. Int $\mathrm{J}$ Gynecol Cancer. 2012;22:9-14.

22. Yamamoto S, Tsuda H, Takano M, Tamai S, Matsubara O. Loss of ARID1A protein expression occurs as an early event in ovarian clear-cell carcinoma development and frequently coexists with PIK3CA mutations. Mod Pathol. 2011; doi: 10.1038/modpathol.2011.189.

23. Yamamoto S, Tsuda H, Takano M, Tamai S, Matsubara O. PIK3CA mutations and loss of ARID1A protein expression are early events in the development of cystic ovarian clear cell adenocarcinoma. Virchows Arch. 2011; [Epub ahead of print]

24. Katagiri A, Nakayama K, Rahman MT, Rahman M, Katagiri H, Nakayama N, Ishikawa M, Ishibashi T, Iida K, Kobayashi $H$, Otsuki Y, Nakayama S, Miyazaki K. Loss of ARID1A expression is related to shorter progression-free survival and chemoresistance in ovarian clear cell carcinoma. Mod Pathol. 2011; [Epub ahead of print]

25. Guan B, Wang TL, Shih IeM. ARID1A, a factor that promotes formation of SWI/SNF-mediated chromatin remodeling, is a tumor suppressor in gynecologic cancers. Cancer Res. 2011;71:6718-27

26. Maeda D, Mao TL, Fukayama M, Nakagawa S, Yano T, Taketani Y, Shih IeM. Clinicopathological Significance of Loss of ARID1A Immunoreactivity in Ovarian Clear Cell Carcinoma. Int J Mol Sci. 2010;11:5120-8

27. Silverberg SG, Mutter GL, Kurman RJ, Kubik-Huch RA, Nogales F, Tavassoli FA. Epithelial tumours and related lesions. In: Tavassoli FA, Devilee P, Eds. World Health Organization Classification of Tumours; Pathology and Genetics of Tumours of the Breast and female genital Organs. Lyon: IARC Press. 2003:221-232.

28. Zorn KK, Bonome T, Gangi L, Chandramouli GV, Awtrey CS, Gardner GJ, Barrett JC, Boyd J, Birrer MJ. Gene expression profiles of serous, endometrioid, and clear cell subtypes of ovarian and endometrial cancer. Clin Cancer Res. 2005;11:6422-30.

29. Vang R, Whitaker BP, Farhood Al, Silva EG, Ro JY, Deavers MT. Immunohistochemical analysis of clear cell carcinoma of the gynecologic tract. Int J Gynecol Pathol 2001;20:252-259

30. Guan B, Mao TL, Panuganti PK, Kuhn E, Kurman RJ, Maeda D, Chen E, Jeng YM, Wang TL, Shih IeM. Mutation and loss of expression of ARID1A in uterine low-grade endometrioid carcinoma. Am J Surg Pathol. 2011;35(5):625-32.

31. Wiegand KC, Lee AF, Al-Agha OM, Chow C, Kalloger SE, Scott DW, Steidl C, Wiseman SM, Gascoyne RD, Gilks B, Huntsman DG. Loss of BAF250a (ARID1A) is frequent in high-grade endometrial carcinomas. J Pathol. 2011;224:328-33.

32. Fadare O, Liang SX. Diagnostic Utility of Hepatocyte Nuclear Factor 1-Beta Immunoreactivity in Endometrial Carcinomas: Lack of Specificity For Endometrial Clear cell Carcinoma. Appl Immunohistochem Mol Morphol, in press

33. Varela I, Tarpey P, Raine K, Huang D, Ong CK, Stephens P, Davies H, Jones D, Lin ML, Teague J, Bignell G, Butler A, Cho J, Dalgliesh GL, Galappaththige D, Greenman C, Hardy C, Jia M, Latimer C, Lau KW, Marshall J, McLaren S, Menzies A, Mudie L, Stebbings L, Largaespada DA, Wessels LF, Richard S, Kahnoski RJ, Anema J, Tuveson DA, Perez-Mancera PA, Mustonen V, Fischer A, Adams DJ, Rust A, Chan-on W, Subimerb C, Dykema K, Furge K, Campbell PJ, Teh BT, Stratton MR, Futreal PA. Exome sequencing identifies frequent mutation of the SWI/SNF complex gene PBRM1 in renal carcinoma. Nature. 2011;469:539-42

34. Xia W, Nagase S, Montia AG, Kalachikov SM, Keniry M, Su T, Memeo L, Hibshoosh H, Parsons R. BAF180 is a critical regulator of p21 induction and a tumor suppressor mutated in breast cancer. Cancer Res. 2008;68:1667-74. 
35. Glaros S, Cirrincione GM, Muchardt C, Kleer CG, Michael CW, Reisman D.The reversible epigenetic silencing of BRM: implications for clinical targeted therapy. Oncogene. 2007;26:7058-66.

36. Reisman DN, Sciarrotta J, Wang W, Funkhouser WK, Weissman BE. Loss of BRG1/BRM in human lung cancer cell lines and primary lung cancers: correlation with poor prognosis. Cancer Res. 2003;63:560-6.

37. Fukuoka J, Fujii T, Shih JH, Dracheva T, Meerzaman D, Player A, Hong K, Settnek S, Gupta A, Buetow K, Hewitt S, Travis WD, Jen J. Chromatin remodeling factors and BRM/BRG1 expression as prognostic indicators in non-small cell lung cancer. Clin Cancer Res. 2004;10:4314-24.

38. Gunduz E, Gunduz M, Ali MA, Beder L, Tamamura R, Katase N, Tominaga S, Yamanaka N, Shimizu K, Nagatsuka H. Loss of heterozygosity at the 9p21-24 region and identification of BRM as a candidate tumor suppressor gene in head and neck squamous cell carcinoma. Cancer Invest. 2009;27:661-8.

39. Lin H, Wong RP, Martinka M, Li G. Loss of SNF5 expression correlates with poor patient survival in melanoma. Clin Cancer Res. 2009;15:6404-11.

40. Sun A, Tawfik O, Gayed B, Thrasher JB, Hoestje S, Li C, Li B. Aberrant expression of SWI/SNF catalytic subunits BRG1/BRM is associated with tumor development and increased invasiveness in prostate cancers. Prostate. 2007;67:203-13. 